\title{
Evaluation the Applicability of the New Torsion Testing Method to Study the Rheological Properties of Materials in a Cold State
}

\section{Pavlov Dmitry and Erpalov Mikhail}

Ural Federal University named after the first President of Russia B.N. Yeltsin, Russia

\section{Abstract}

The most important parameter characterizing the rheological properties of steels and alloys is the strain resistance. The new method of testing cylindrical specimens for torsion with variable grip's acceleration proposed (application No. 2018132149 of 07.09.2018 for the patent of the Russian Federation for the invention). This method is designed to study the rheological properties of steels and alloys mainly in a hot state. However, this method is universal and can be used to determine strain resistance of

Corresponding Author:

Pavlov Dmitry

d.a.pavlov@urfu.ru

Received: 25 February 2019

Accepted: 9 April 2019

Published: 15 April 2019

Publishing services provided by

Knowledge E

(c) Pavlov Dmitry and Erpalov

Mikhail. This article is distributed

under the terms of the

Commons Attribution License,

which permits unrestricted use

and redistribution provided that

the original author and source

are credited.

Selection and Peer-review under

the responsibility of The Ural

school-seminar of metal

scientists-young researchers

Conference Committee. materials in a cold state. The article is devoted to the applicability evaluation of the proposed torsion testing method to study the rheological properties of materials in a cold state. It's done on a basis of the comparison of the hardening curves obtained during the testing of specimens for tensile and torsion. The CrWMn steel was used. The results show that the hardening curves obtained during the torsion and tensile tests are close, and the yield stress values differ by about 3\%. It can be assumed that the developed method of torsion testing allows to obtain reliable values of the material's strain resistance in a cold state.

Keywords: hardening curves, strain resistance, torsion test, tensile test, test control, post-processing, experimental laboratory setup

The study was made within the base part of state job in the field of scientific activity $N^{\circ} 11.9538 .2017 / 8.9$, supported by Act 211 of the Government of the Russian Federation (agreement No. 02.A03.21.0006).

\section{Introduction}

One of the most important parameters characterizing mechanical properties of metals and alloys is strain resistance. Knowledge of this parameter allows to develop any production technologies, allows to perform engineering design as well as to calculate 
the power parameters of metal forming processes. The strain resistance of materials is determined in experiments. The most common methods of testing are tensile and compressing. Torsion testing is less common due to less knowledge of this process in a hot state of material and the lack of wide application for the certification of products in production. However, testing specimens in torsion has more opportunities compared to the widely used methods of testing. For example, the strain rate in torsion testing can be tens or hundreds of times greater than the tensile and compression values. The possibility of high strain rates in determining the strain resistance is important for production, because many metal forming processes are high-speed. However, the existing methods of torsion tests [1-6] have limitations associated with the inability to obtain reliable values of the strain resistance of materials in a hot state, since they take into account the effects of strain-rate hardening or softening of materials not fully.

The new method of testing cylindrical specimens for torsion with variable grip's acceleration proposed in application No. 2018132149 of 07.09 .2018 for the patent of the Russian Federation for the invention. This method allows accurate determining the strain resistance of materials in a hot state. A distinctive feature of this method is the use specimen-loading mode with variable grip's acceleration. In addition, this method is universal and can be used to determine strain resistance of materials in a cold state. The article is devoted to the applicability evaluation of the proposed torsion testing method to study the rheological properties of materials in a cold state.

\section{Description of the New Torsion Test Method}

Torsion tests are carried out at a constant temperature value $\theta$ of the gauge of a specimen. During the test, determine the values of the angle of twist $\varphi$, as well as the torque $M$, which provides for the plastic deformation of the gauge of a specimen. At the beginning of testing up to a point of time $t^{*}$, the monotonous increase of the twist angle is carried out. Starting from the point of time $t^{*}$, ensure compliance with the condition

$$
k=\frac{\xi}{\epsilon}=\text { const }
$$

where $\varepsilon$ and $\xi$ - strain and strain rate values.

The point of time $t^{*}$ can be determined as

$$
t^{*}=\frac{2}{k}
$$


In the case of using specimens with a cylindrical gauge of the radius $r$ and length I the values of the twist angle $\varphi$ are changed in accordance with the expression

$$
\left\{\begin{array}{l}
\phi=\frac{\sqrt{3}}{4} \frac{l}{r} c k^{2} e^{2} t^{2}, \quad t \leq t^{*} ; \\
\phi=\sqrt{3} \frac{l}{r} c e^{k t}, \quad t \geq t^{*},
\end{array}\right.
$$

where $c$ and $k$ - parameters with an arbitrary value.

The grip's angular velocity values can be determined in accordance with the expression

$$
\left\{\begin{array}{l}
\omega=\frac{\sqrt{3}}{2} \frac{l}{r} c k^{2} e^{2} t, \quad t<\frac{2}{k} ; \\
\omega=\sqrt{3} \frac{l}{r} c k e^{k t}, \quad t \geq \frac{2}{k} .
\end{array}\right.
$$

Eq. (3) and (4) determine a test control algorithm. The experimental data postprocessing algorithm is as to calculate the values of material's shear strain resistance on a basis of only the torque and twist angle dependence on time:

$$
\tau_{s}(\epsilon, \xi, \theta)=\frac{1}{2 \pi r^{3}}\left(3 M+\frac{d M}{d \epsilon} \epsilon\right),
$$

where $\epsilon=\frac{1}{\sqrt{3}} r \frac{\phi}{l}, \xi=k \epsilon$.

When the maximum strain and strain rate values are assigned, the duration of the test can be determined using one of the formulas

$$
t_{\mathrm{end}}=\frac{1}{k} \ln \left(\frac{\epsilon^{\max }}{c}\right)
$$

or

$$
t_{\mathrm{end}}=\frac{1}{k} \ln \left(\frac{\xi^{\max }}{c k}\right) .
$$

Described above testing method with the variable grip's acceleration is suitable for studying the rheological properties of materials both in a hot and a cold states, since it takes into account the effects of strain-rate hardening or softening of materials fully.

\section{Research Method and Equipment}

In order to verify the accuracy of strain resistance definition with the use of proposed method the comparison of the hardening curves obtained during the testing of specimens for tensile and torsion in a cold state is carried out. During cold deformation the strain resistance does not depends or depends weakly on a strain rate [7]. So, the results of the torsion and tensile tests can be compared. 
Fig. 1 shows general appearance of the laboratory test setup for the torsion tests of materials in a cold and a hot state. Technical characteristics of the laboratory test setup are presented in Table 1.

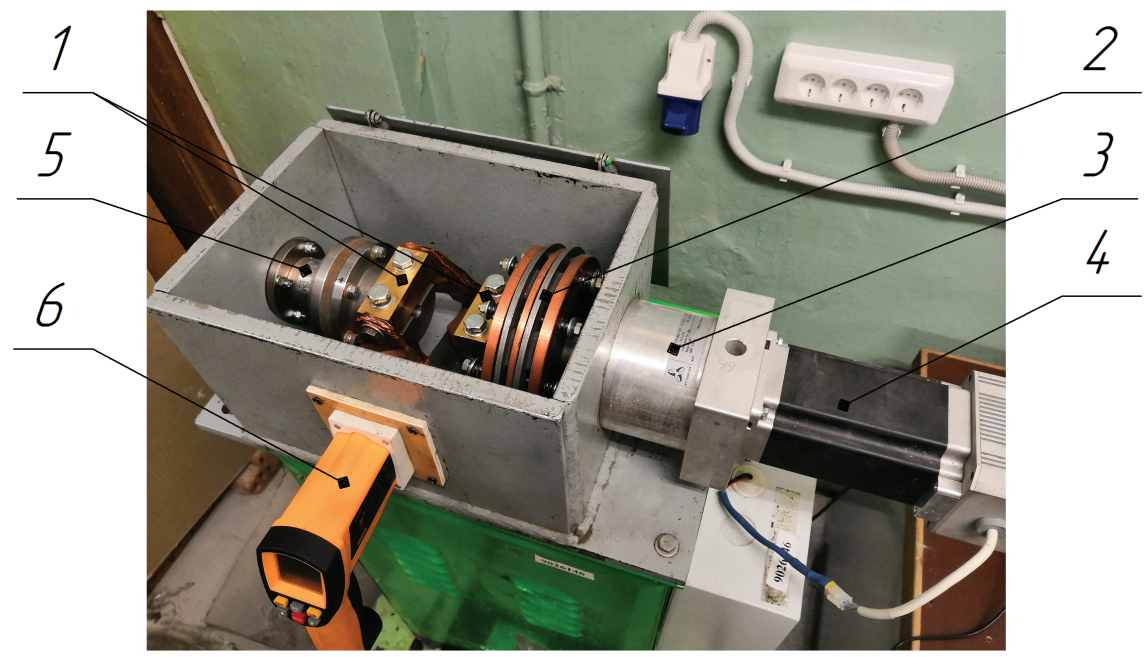

1 - grips of laboratory test setup; 2 - electric contact heating device; 3 - reduction gearbox; 4 - stepping motor; 5 - torque detector; 6 - pyrometer

Figure 1: General appearance of the laboratory test setup for the torsion tests.

TABLE 1: Technical characteristics of the laboratory test setup.

Characteristic
Overall size:
- in length
- in width
- in height
Weight
Power demand (peak at the time of heating)
Flow of heating
Voltage
Maximum torque
Maximum heating temperature
Maximum strain rate
Maximum frequency of the alternating torsion

\begin{tabular}{|c|}
\hline Unit \\
\hline $\mathrm{mm}$ \\
\hline $\mathrm{mm}$ \\
\hline $\mathrm{mm}$ \\
\hline $\mathrm{kg}$ \\
\hline $\mathrm{kW}$ \\
\hline $\mathrm{kA}$ \\
\hline V \\
\hline $\mathrm{N} \cdot \mathrm{m}$ \\
\hline${ }^{\circ} \mathrm{C}$ \\
\hline $1 / \mathrm{s}$ \\
\hline $\mathrm{Hz}$ \\
\hline
\end{tabular}

\begin{tabular}{|c|}
\hline Value \\
\hline 750 \\
\hline 325 \\
\hline 990 \\
\hline 150 \\
\hline 10 \\
\hline 3,7 \\
\hline $220 / 380$ \\
\hline 70 \\
\hline 1250 \\
50 \\
\hline 5
\end{tabular}

Tensile tests were carried out on the INSTRON 3382 tensile testing machine. The technical characteristics of INSTRON 3382 are presented in Table 2.

Rod of tool alloy steel CrWMn was used for the preparing the specimens. Table 3 shows the chemical composition of the material taken for the experiment. Specimens for torsion and tensile testing had the same shape (Fig. 2), but on the specimen for torsion test, the flats were made in order to transmitting a torque from the grips. 
TABLE 2: Technical characteristics of the INSTRON 3382.

Characteristic
Maximum load
Maximum traverse stroke
Range of traverse speed
Traverse speed error
Positioning accuracy of the traverse
Heating temperature
Accuracy of temperature maintenance

Unit
$\mathrm{kN}$
$\mathrm{mm}$
$\mathrm{mm} / \mathrm{min}$
$\%$
$\mathrm{micron}$
${ }^{\circ} \mathrm{C}$
${ }^{\circ} \mathrm{C}$

\begin{tabular}{|c|}
\hline Value \\
\hline 100 \\
\hline 840 \\
\hline $0.001-250$ (up to $50 \mathrm{kN}$ ) \\
$0.001-100$ (up to $100 \mathrm{kN}$ ) \\
\hline 0.2 \\
\hline 0.03 \\
\hline 1000 \\
\hline+3
\end{tabular}

The dimensions of the tensile specimen are those shown in the Fig. 3. Radius $r$ and length / of cylindrical gauge of the torsion specimen are equal to $3.25 \mathrm{~mm}$ and 17.8 $\mathrm{mm}$ respectively. In accordance with the proposed method of testing, the values of parameters $c$ and $k$ were assigned equal to 0.00676676 and 1 respectively.

TABLE 3: Chemical composition of CrWMg steel.

\begin{tabular}{|c|c|c|c|c|c|c|c|c|c|}
\hline Element & C & $\mathrm{Cr}$ & W & $\mathrm{Mn}$ & $\mathrm{Si}$ & $\mathrm{Ni}$ & $\mathrm{Cu}$ & $\mathrm{S}$ & $P$ \\
\hline Content, \% & $0.9-1.05$ & $0.9-1.2$ & $1.2-1.6$ & 0.8-1.1 & $0.1-0.4$ & 0.4 & 0.3 & 0.03 & 0.03 \\
\hline
\end{tabular}

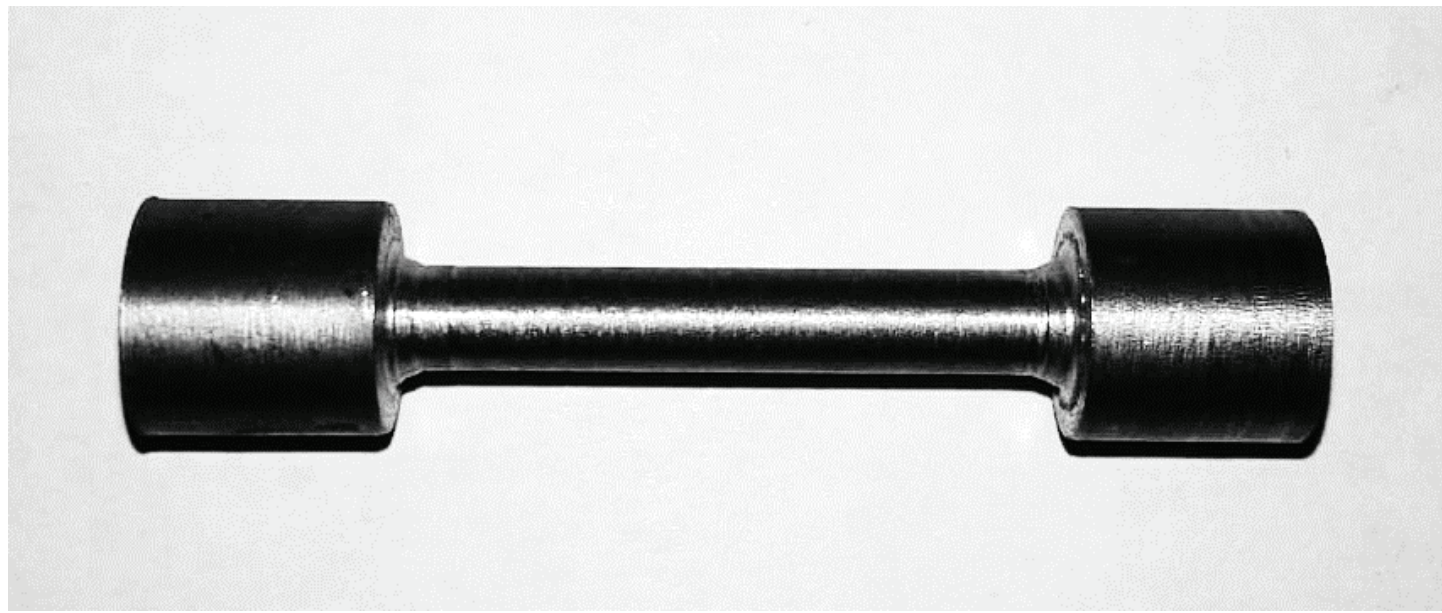

Figure 2: Specimen photo.

In order to perform torsion test in according to the proposed method the test control program on Servo Motor Language was developed. The torsion angle of the stepping motor shaft was controlled by specifying the sample spacing of the controlling action, as well as a set of values of angular velocity of the motor shaft for each sampling interval. These values were calculated on the basis of Eq. (3) and (4) using Microsoft Excel and loaded into the EEPROM (Electrically Erasable Programmable Read-Only Memory) of the stepping motor controller. Fig. 4 shows time laws of twist angle and angular velocity of 


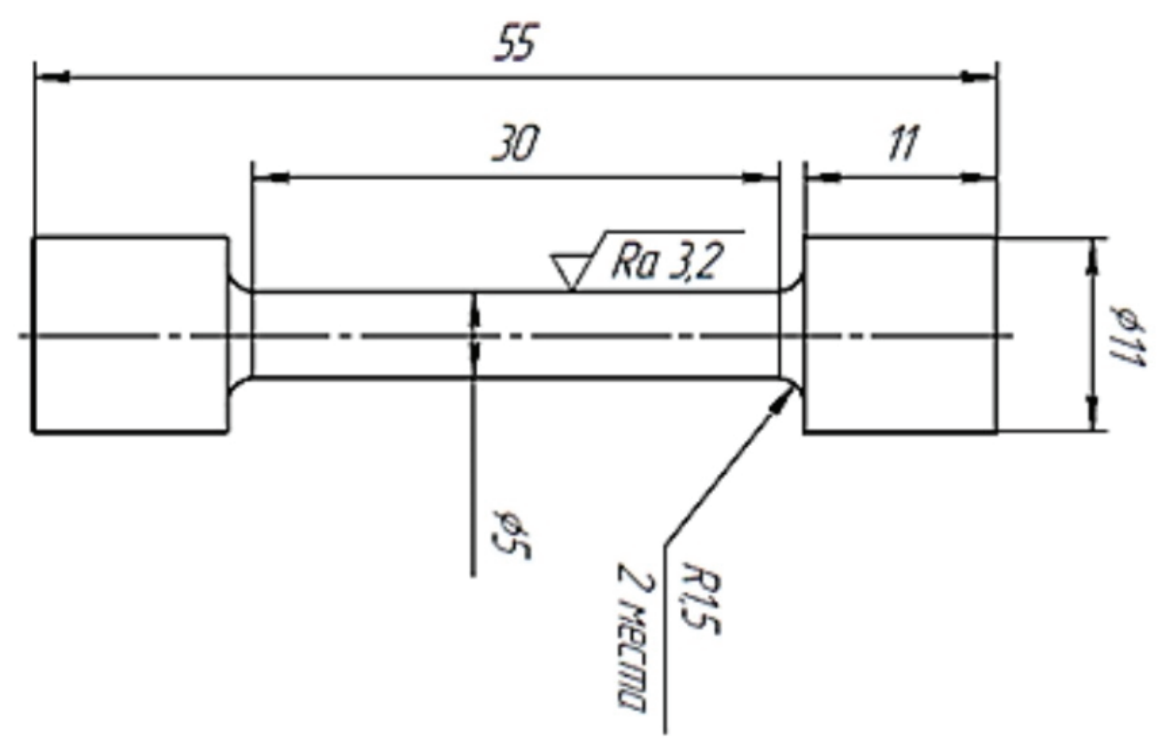

Figure 3: Dimensions of test specimen for tensile.

motor shaft. The values of the twist angle are given by a number of impulses of the builtin encoder, one complete rotation of the motor shaft is equal to 8,000 impulses. The gear ratio of the reduction gear-box is 10 .

Post-processing of experimental data was carried out as follows. Starting from the time point $t^{*}$, the values of the torque and twist angle were recorded with the help of sensors. The torque values presented in tabular data have been post-processed in order to remove the high frequency component from the signal, which leads to errors in the calculation of the derivative (see Eq. 5). The Low Pass Filter function implemented in Wolfram Mathematica software was used for this purpose.

The initial data for the tensile test at the INSTRON 3382 were the diameter and length of the working part of the specimen (see Fig. 3) as well as stretching speed. The stretching speed of tensile specimen was equal to $5 \mathrm{~mm} / \mathrm{min}$. During the test, the tensile force and elongation of specimen's gauge were recorded, followed by computer processing of the data.

\section{Results of the Study}

The values of shear strain resistance were determined by Eq. 5 . The obtained data were recalculated to the values of the strain resistance by multiplying by a factor equal to $\sqrt{3}$ and compared with the strain resistance values found in tensile test. Stress-strain curves obtained as a result of torsion and tensile tests are presented in Fig. 5. 


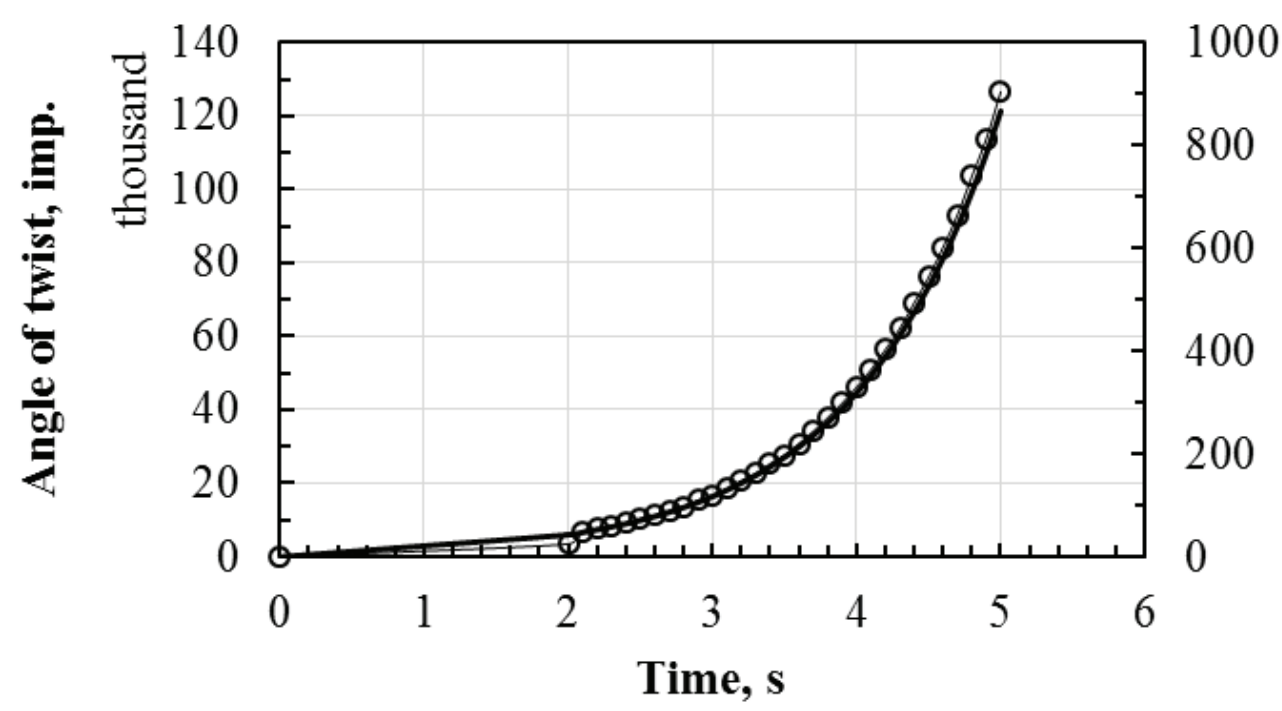

\section{- Angle of twist $\quad-$ - Angular velosity}

Figure 4: Time laws of twist angle and angular velocity of motor shaft.

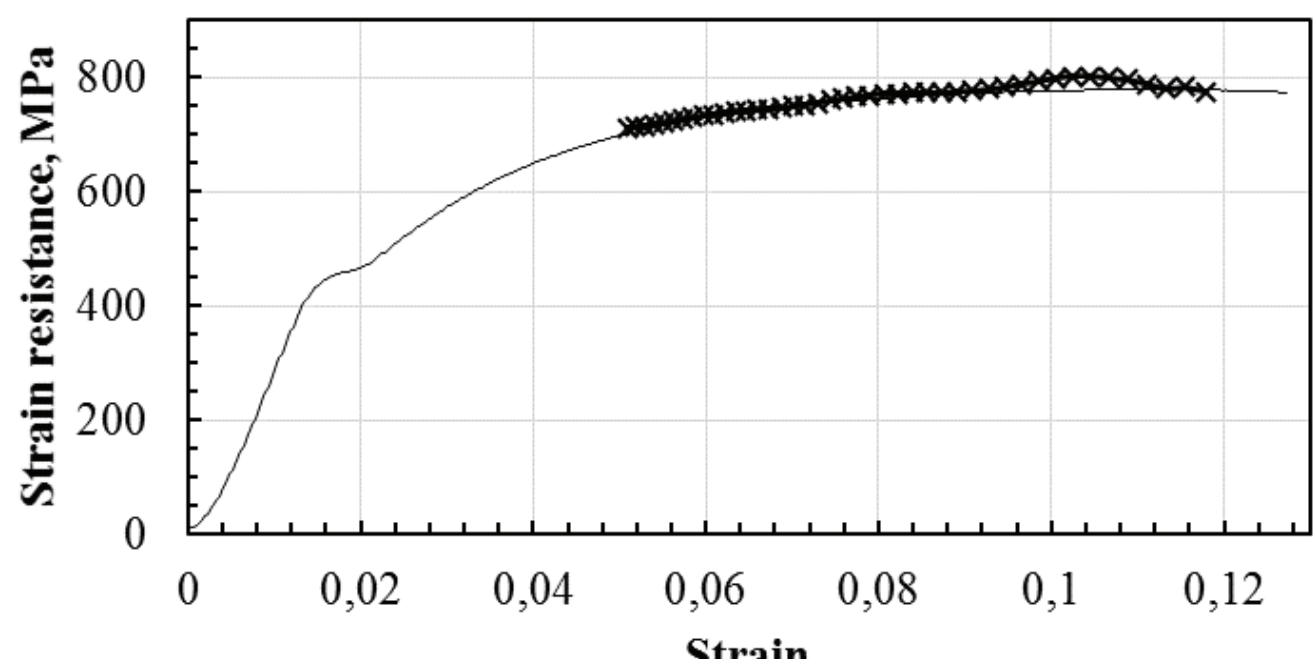

Strain

- tensile test $\quad *$ torsion test

Figure 5: Stress-strain curves.

Fig. 5 shows that hardening curves are close to each other. In torsion, the value of yield stress was equal to $802 \mathrm{MPa}$, and in tensile - $779 \mathrm{MPa}$. The difference in the yield stress values is $3 \%$. It is possible to consider that the developed method of testing the cylindrical specimens for torsion as well as the test control and post-processing algorithms are reliable. For experimental verification of the proposed method of studying the rheological properties of materials in a hot state, it is necessary to conduct further 
researches. However, the efficiency of the method for studying the properties in a cold state can be considered confirmed.

\section{Summary}

The article describes a new method of torsion testing, as well as the algorithm and program to control laboratory test setup and post-processing algorithm. The hardening curves obtained during the tensile and torsion tests were compared. It is established that during the torsion tests according to the proposed method at room temperature, it is possible to obtain reliable values of strain resistance of the material, since the hardening curves are close to each other, and the values of the yield stress differ by only $3 \%$. Thus, the reliability of the proposed method of testing for torsion during cold deformation is confirmed. The purpose of further research is to confirm the efficiency of the developed method during a hot deformation of specimen.

\section{References}

[1] A. Nadai, Theory of flow and fracture of solids, Volume II, McGraw-Hill Bool Company, Inc., New York, 1963.

[2] D.F. Fields, W.A. Backofen, Determination of strain-hardening characteristics by torsion testing, in: Proceedings of the 6th annual meeting of the society, ASTM Proceeding, 1957, pp. 1259-1272.

[3] S. Khoddam, P.D. Hodgson, Post processing of the hot torsion test results using a multi-dimensional modelling approach, Materials \& design. $31-5$ (2010) 2578-2584.

[4] J.J. Jonas, F. Montheillet, L.S. Toth, C. Ghoh, Effects of varying twist and twist rate sensitivities on the interpretation of torsion testing data, Materials Science \& Engineering. 591 (2014) 9-17.

[5] T. Sheppard, D.S. Wright, Determination of flow stress: Part 1. Constitutive equation for aluminum alloys at elevated temperatures, Metals Technology. 6 (1979) 215-223.

[6] K. Laber, A. Kawalek, S. Sawicki, H. Dyja et.al., Application of torsion test for determination of rheological properties of 5019 aluminium alloy, Key Engineering Materials. 682 (2016) 356-361.

[7] Yu.N. Loginov, S.L. Demakov, A.G. Illarionov, and A.A. Popov, Effect of the Strain Rate on the Properties of Electrical Copper, Russian Metallurgy (Metally). 2011-3 (2011) 194201. 